\title{
Twenty-Four-Hour Variation of Intraocular Pressure in Primary Open-Angle Glaucoma Treated with Triple Eye Drops
}

\author{
Yoshinori Itoh, ${ }^{1}$ Kenji Nakamoto, ${ }^{2,3}$ Hiroshi Horiguchi, ${ }^{1}$ Shumpei Ogawa, ${ }^{1,4}$ \\ Takahiko Noro, ${ }^{1,5}$ Makoto Sato, ${ }^{6}$ Tadashi Nakano, ${ }^{1}$ Hiroshi Tsuneoka, ${ }^{1}$ and Noriko Yasuda $^{7}$ \\ ${ }^{1}$ Department of Ophthalmology, Jikei University School of Medicine, Tokyo, Japan \\ ${ }^{2}$ Department of Ophthalmology, Tokyo Metropolitan Police Hospital, Tokyo, Japan \\ ${ }^{3}$ Department of Ophthalmology, Nippon Medical School, Tokyo, Japan \\ ${ }^{4}$ Department of Ophthalmology, Atsugi City Hospital, Atsugi, Japan \\ ${ }^{5}$ Tokyo Metropolitan Institute of Medical Science, Tokyo, Japan \\ ${ }^{6}$ Department of Ophthalmology, Niizashiki Central General Hospital, Tokyo, Japan \\ ${ }^{7}$ Department of Ophthalmology, Showa University School of Medicine, Tokyo, Japan \\ Correspondence should be addressed to Yoshinori Itoh; yonchiku33@gmail.com
}

Received 4 August 2016; Revised 23 January 2017; Accepted 12 March 2017; Published 3 May 2017

Academic Editor: Antonio M. Fea

Copyright (c) 2017 Yoshinori Itoh et al. This is an open access article distributed under the Creative Commons Attribution License, which permits unrestricted use, distribution, and reproduction in any medium, provided the original work is properly cited.

\begin{abstract}
Objectives. To evaluate 24-hour intraocular pressure (IOP) variation in patients with primary open-angle glaucoma (POAG) treated with triple eye drops. Subjects and Methods. The IOP was measured in 74 eyes in 74 POAG patients (seated) on triple therapy (PG analogue, $\beta$-blocker, carbonic anhydrase inhibitor) at about every 3 hours. Results. The peak IOP was $13.5 \pm 3.1$ at 1:00, and the trough IOP was at $12.6 \pm 2.4 \mathrm{mmHg}$ at 7:00. The IOP at 7:00 was significantly lower than that at 10:00, 1:00, and 3:00 $(p<0.05)$. Based on the time of the peak IOP, we classified the patients into two groups: diurnal $(28$ eyes $)$ and nocturnal types (37 eyes). There was significant difference at the spherical equivalent between diurnal and nocturnal types $(p=0.014)$. To assess the influence of reflective error, we conducted subanalysis for two groups: high myopic (26 eyes, $\leq-6 \mathrm{D})$ and low/ nonmyopic (24 eyes, $\geq-2 \mathrm{D}$ ) groups. In the low/nonmyopia group, the IOP was significantly higher at 1:00 and 3:00 than at 13:00, 16:00, and 7:00 $(p<0.05)$. Conclusion. The mean of IOP elevated outside of clinic hour in the POAG patients on triple therapy. The low/nonmyopia patient should be carefully treated because the IOP of the patients at night elevated significantly.
\end{abstract}

\section{Introduction}

The intraocular pressure (IOP) reduction is the only evidence-based treatment for glaucoma [1-4]. The IOP in glaucoma patients is generally evaluated in single IOP measurement during clinic hours, although IOP varies over the course of 24 hours. Hence, it is obvious that understanding 24-hour IOP variation is important in glaucoma treatment.

Approximately 100 years ago, Maslenikow reported that IOP was generally higher during daytime than nighttime [5]. The biological clock in the suprachiasmatic nucleus, the central clock that regulates the circadian rhythm, controls aqueous humor production via sympathetic nervous system. Therefore, the IOP variation due to aqueous humor production is less at night than during daytime [6-9]. In general, the IOP variation pattern in the sitting position peaks in the morning and decreases toward midnight [10]. However, the IOP variation is affected by various factors such as posture and spherical equivalent [11].

In primary open-angle glaucoma (POAG), generally, the first-line treatment to reduce IOP is an instillation of eye drops. Daytime peak IOP is clinically important in predicting long-term glaucomatous progress in the patients treated with one or two kinds of eye drops because the IOP peaks at night in only $20 \%$ of cases [12]. In some cases, however, visual field defects progress quickly in spite of adequate reduction of IOP measured during clinic hours. The next step of treatment is usually to add eye drops up to three or four different types. 
TABLE 1: Combinations of eye drops used by the patients in this study. Data is expressed as number of patients. All patients were treated with three different types of eye drops; PG, CAI, and $\beta$-blocker, in different combinations.

\begin{tabular}{lccccc}
\hline Prostaglandin & \multicolumn{2}{c}{ Latanoprost } & Travoprost & Tafluprost & Bimatoprost \\
\hline$\beta$-blocker & $\begin{array}{c}\text { Carteolol } \\
\text { hydrochloride } \\
2 \% 2 \text { times/1 time }\end{array}$ & $\begin{array}{c}\text { Timolol } \\
\text { maleate } 0.5 \%\end{array}$ & $\begin{array}{c}\text { Carteolol } \\
\text { hydrochloride } \\
2 \% 1 \text { time }\end{array}$ & $\begin{array}{c}\text { Carteolol time } \\
\text { hydrochloride } \\
2 \% 2 \text { times/1 time }\end{array}$ & $\begin{array}{c}\text { Carteolol } \\
\text { hydrochloride } 2 \text { times/1 time }\end{array}$ \\
CAI & $4 / 1$ & $5 / 10$ & 1 & $1 / 0$ & $1 / 0$ \\
Dorzolamide 1\% & $11 / 4$ & $7 / 22$ & 3 & $0 / 1$ & $2 / 1$ \\
Brinzolamide 1\% & & & & 1 & \\
\hline
\end{tabular}

Importantly, combinations of eye drop treatment affect the pattern of the IOP variation. In many cases, the IOP during eye drop treatment peaks outside clinic hours $[13,14]$. Moreover, the effective IOP-lowering durations vary among eye drops, which may also lead to the IOP variation. Unlike $\beta$-blockers, prostaglandin analogs (PG) and carbonic anhydrase inhibitor (CAI) lower the IOP significantly throughout 24 hours. During $\beta$-blocker treatment, the IOP is higher during daytime than at night [15-17].

When treated with multiple eye drops, combinations of drops generally flatten the IOP variation $[18,19]$. Nakakura et al. found that the 24-hour IOP in patients treated with multiple eye drops tended to peak at night and that it was impossible to estimate the peak IOP based only on an IOP measured during daytime because there was no relationship between daytime and nighttime IOP [20]. In the present study, we measured 24-hour IOP variation in patients with POAG treated with triple eye drops and investigated the relationship with patient background factors including spherical equivalent.

\section{Methods}

Seventy-four outpatients (aged 54.6 \pm 12.4 years, 37 males and 37 females) with POAG at the Department of Ophthalmology, Tokyo Metropolitan Police Hospital, Japan were studied. We randomly chose the right or left eye in the patients who had glaucoma in the both eyes. The subjects gave consent to be hospitalized for 24-hour IOP measurement. All patients were treated with three different types of eye drops: PG (latanoprost, travoprost, tafluprost, or bimatoprost), $\beta$-blocker $(0.5 \%$ timolol maleate or $2 \%$ carteolol hydrochloride), and CAI ( $1 \%$ dorzolamide or $1 \%$ brinzolamide). The combinations of eye drops used by the patients are shown in Table 1.

The diagnostic criteria of POAG were as follows: normal open-angle; characteristic glaucomatous optic neuropathy with diffuse or focal optic rim thinning, cupping, or nerve fiber layer defects indicative of glaucoma and corresponding visual field changes according to Anderson and Patella criteria [21]; and presence of no other ocular, rhinological, neurological, or systemic disorders potentially causing optic nerve damage. Exclusion criteria were a history of cardiac or respiratory disorders; severe corneal disease, uveitis, or previous eye surgery; and concomitant use of any systemic medication that might affect the IOP.
We used the data of the patient that did not conflict with the above-mentioned exclusion criteria among the patients which have measured the IOP of 24-hour of treated with triple eye drops. Patients were hospitalized for 24-hour IOP measurement. In all patients, the IOP was measured in the sitting position by one ophthalmologist using a Goldmann applanation tonometer (Haag-Streit, Bern, Switzerland) averages of 3 times at the following hours: 10:00, 13:00, $16: 00,19: 00,22: 00,1: 00,3: 00$, and 7:00. Five glaucoma specialists were involved in this study to measure the IOP of 74 eyes. During hospitalization, patients self-administered eye drops. For nighttime IOP measurements, patients were waken gently and walked 10-20 meters to the tonometer. The patients returned to bed immediately after the IOP measurement.

To facilitate assessment of the relationship between 24-hour IOP variation and demographic and clinical characteristics (age, difference between peak and trough IOP, baseline IOP at 10:00, and spherical equivalent refraction), we classified the patients into two groups: diurnal and nocturnal types. In diurnal type, daytime IOP (averaged IOP for 7:00, 10:00, and 13:00) was higher than the nighttime IOP (averaged IOP for 22:00, 1:00, and 3:00). Whereas nocturnal type, the nighttime IOP was higher than daytime IOP (Figure 1).

A Humphrey Field Analyzer (Carl Zeiss Meditec, Dublin, CA, USA) was used with program 30-2 for evaluating visual field in the patients. The mean deviation averaged across all eyes was $-11.3 \mathrm{~dB}$. We measured objective spherical equivalent refraction with an auto refractometer (Nidek ARK530- $\left.{ }^{\circledR}\right)$. For statistical analysis, the repeated measures ANOVA, the Mann-Whitney $U$ test, and two-way repeated measures ANOVA were used at a significance level of $p<0.05$ (two-sided test). Statistical analysis was conducted using SPSS (SAS Institute, Cary, NC) and Matlab ${ }^{\circledR}$ (The MathWorks Inc Natick, MA).

\section{Results}

Figure 2 shows the variation of mean IOP at all time points of measurement for 74 eyes of 74 subjects treated with triple eye drops. The peak IOP was $13.5 \pm 3.1$ (mean $\pm \mathrm{SD}$ ) $\mathrm{mmHg}$ measured at 1:00, and the trough IOP was $12.6 \pm 2.4 \mathrm{mmHg}$ measured at $7: 00$. The trough IOP was significantly lower than the IOP at 1:00, 3:00, and 10:00 $(p=0.0066,0.035$, and 0.049 , resp., repeated measures ANOVA).

Figure 3 shows the histograms of 24-hour IOP fluctuation defined as the difference between peak and trough IOP. The 


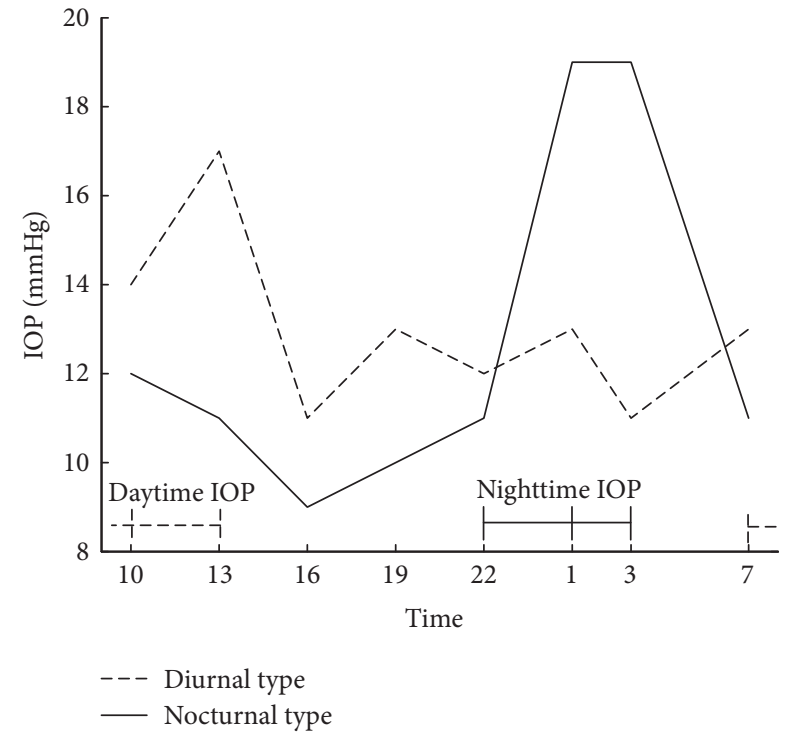

FIGURE 1: Typical examples of diurnal type and nocturnal type IOP profiles. Dashed line shows 24-hour IOP in a representative subject of diurnal type. In this patient, the averaged IOP for 7:00, 10:00, and 13:00 (daytime IOP) was higher than the averaged IOP for 22:00, 1:00, and 3:00 (nighttime IOP). Solid line shows 24-hour IOP of a representative subject of nocturnal type, in whom nighttime IOP was higher than daytime IOP.

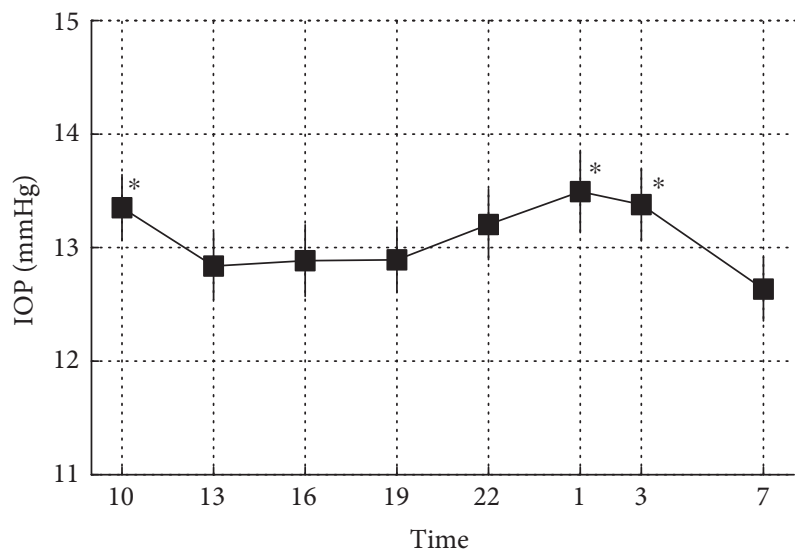

FIGURE 2: Mean 24-hour IOP at all time points of measurement in 74 eyes of 74 patients. Square indicates mean IOP of all eyes. The IOP at 7:00 was significantly lower than that at 10:00, 1:00, and 3:00. Error bar indicates standard deviation. ${ }^{*}$ Higher than 7:00 $(p<0.05)$.

IOP fluctuation was within $10 \mathrm{mmHg}$ in all subjects. Mean ( \pm SD) 24 -hour IOP variation was $3.3 \pm 1.5 \mathrm{mmHg}(95 \%$ confidence interval: $3.16-3.96 \mathrm{mmHg}$ ). The majority of 24-hour IOP fluctuation ranged from 2 to $6 \mathrm{mmHg}$. The 24-hour IOP fluctuation was $3 \mathrm{mmHg}$ or more in 55 eyes even though all patients adhered to treatment with triple eye drops.

The histogram in Figure 4 shows the time when the peak IOP was measured in 55 eyes with IOP fluctuation of

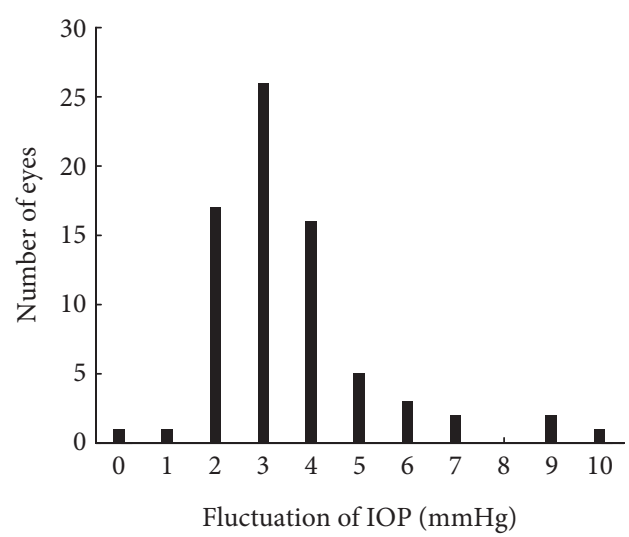

FIgURE 3: Distribution of 24-hour IOP variation among 74 eyes. Histogram shows the number of eyes with each variation.

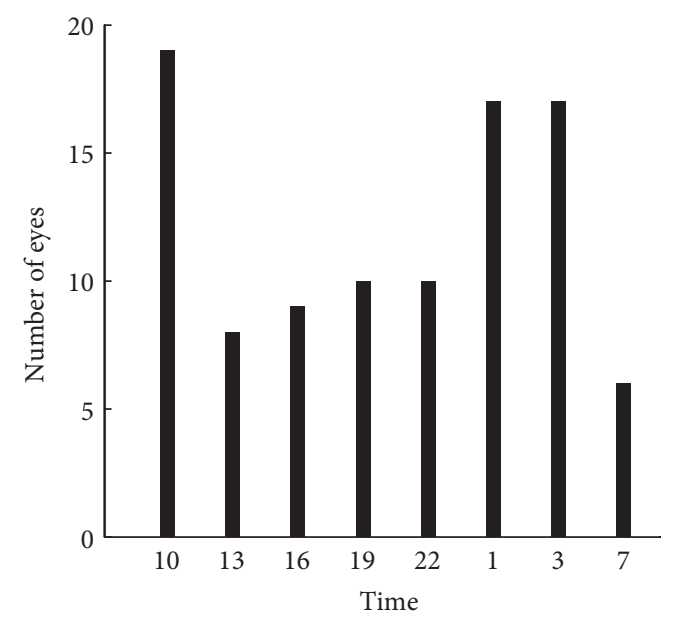

FIgUre 4: Time when peak IOP was measured. Histogram shows the number of eyes with each peak IOP time.

$3 \mathrm{mmHg}$ or more allowing repetition in one eye that showed two or more peaks (Figure 4). The peak IOP was measured in 19 eyes at 10:00 (19.8\%), 17 eyes at 1:00 (17.7\%), and 17 eyes $(17.7 \%)$ at $3: 00$. Sixty eyes $(62.5 \%)$ did not have peak IOP during office hours. Note that the time of peak IOP was outside clinic hours in many eyes.

We compared diurnal type to nocturnal type to assess the relationship between 24-hour IOP variation and demographic and clinical characteristics. Eyes with 24-hour IOP fluctuation of $2 \mathrm{mmHg}$ or less $(n=9)$ were excluded in subsequent analyses because the aim of the subanalysis is to assess causes of the 24-hour IOP variation in the patients. Eventually, 65 eyes were analyzed; 28 and 37 eyes belonged to diurnal type and nocturnal type, respectively (Table 2).

Based on the classification, the average IOP at 10:00 in diurnal type was significantly higher than that in nocturnal type. Moreover, the spherical equivalent and IOP variation in nocturnal type were significantly greater than those in 
TABLE 2: Comparison of background factors between diurnal and nocturnal types of IOP profile. Data are expressed as mean \pm SD. Significant differences in spherical equivalent, variation of IOP and IOP at 10:00 were observed between diurnal and nocturnal types.

\begin{tabular}{lccc}
\hline & Diurnal type $(n=28)$ & Nocturnal type $(n=37)$ & $p$ value \\
\hline Age (y) & $51.9 \pm 10.5$ & $56.1 \pm 14.1$ & 0.18 \\
Spherical equivalent (D) & $-5.7 \pm 4.0$ & $-4.0 \pm 4.0$ & 0.014 \\
Mean deviation (dB) & $-10.8 \pm 8.6$ & $-11.7 \pm 9.3$ & 0.81 \\
24-hour fluctuations of IOP (mmHg) & $3.1 \pm 1.1$ & $4.2 \pm 2.0$ & 0.01 \\
IOP at 10:00 (mmHg) & $14.1 \pm 2.4$ & $12.7 \pm 2.4$ & 0.01 \\
\hline
\end{tabular}

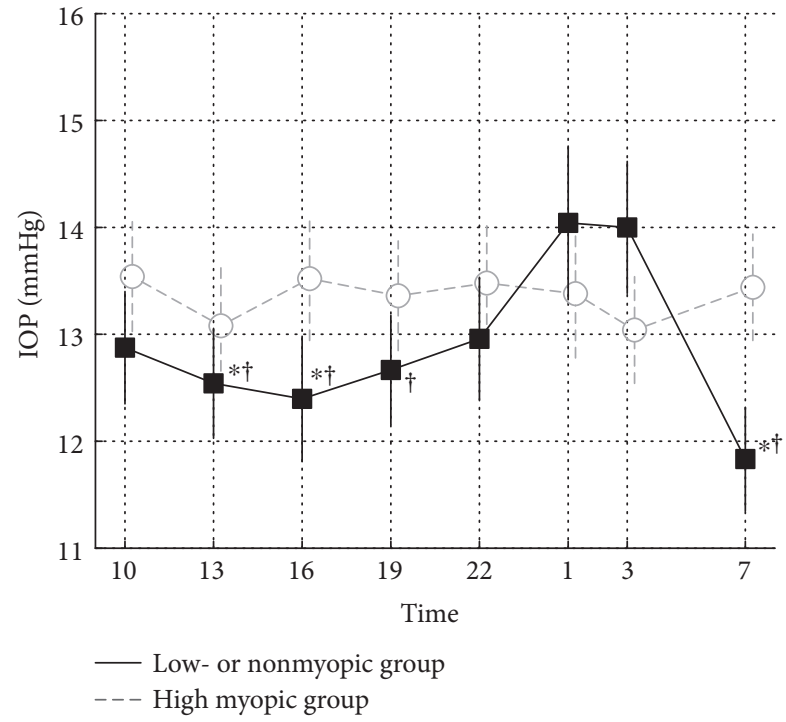

FIGURE 5: Comparison of 24-hour IOP variation in two groups with different spherical equivalent refraction. Gray dashed line and circles indicate mean IOP in high myopic group (HM). Black solid line and squares indicate mean IOP in low- or nonmyopic group (LNM). Error bar indicates standard deviation. * Lower than 3:00 $(p<0.05)$. ${ }^{\dagger}$ Lower than 1:00 $(p<0.05)$.

diurnal type $(p<0.05)$. There were no significant differences in age and mean deviation of HFA between diurnal and nocturnal types.

To perform a subanalysis according to spherical equivalent, we classified into three groups: high myopic, moderate myopic, and low or nonmyopic groups. We compared the 24-hour IOP variation between the high myopic (HM: less than $-6 \mathrm{D}, 26$ eyes) and low or nonmyopic groups (LNM: more than $-2 \mathrm{D}, 24$ eyes).

Figure 5 shows the mean 24-hour IOP of HM and LNM. The 24-hour IOP variation in HM was relatively small. On the other hand, the 24-hour IOP in LNM tended to increase at nighttime. There were no significant differences between two groups at all time points. Only in LNM, however, mean IOP at 13:00, 16:00, 19:00, and 7:00 was significantly lower than that at 1:00 and/or 3:00 $(p<0.05$, two-way repeated measures ANOVA). The IOP at 3:00 was significantly higher than the IOP at 13:00, 16:00, and 07:00. Additionally, the LNM IOP at 3:00 was significantly higher than the IOP at
13:00, 16:00, 19:00, and 7:00, whereas there was no significant difference in HM group.

\section{Discussion}

This study determined the 24-hour IOP variation in patients treated with triple eye drops. The IOP measured in the sitting position normally peaks in the morning and declines toward the evening [10]. In patients on triple eye drop treatment, although the IOP level was higher at 10:00. Compared with other time points during the day, the peak was at 1:00 (13.5 $\pm 3.1 \mathrm{mmHg})$ and IOP remained at a significantly higher level at 3:00 compared to other time points.

Similar to our study, Nakakura et al. examined the 24-hour IOP variation in patients on triple eye drop treatment and found that IOP was the highest outside clinic hours in $66.2 \%$ of patients, while IOP was the lowest during clinic hours in $72.5 \%$ [20]. The present study also found that the highest IOP was outside clinic hours in $62.5 \%$ of subjects, which was in good agreement with the findings of Nakakura et al. These results suggest that triple eye drop treatment markedly changes the pattern of the 24-hour IOP variation and reduces the IOP variation, but is associated with a risk of the IOP elevation during nighttime (outside clinic hours). Moreover, Konstas et al. reported that the IOP with multiple eye drops elevated at night, and the peak IOP was $14.2 \pm 3.8 \mathrm{mmHg}$ at 2:00 measuring the 24-hour IOP [22].

The mechanism by which IOP tended to increase at nighttime in patients treated with triple eye drops is not known. Since the parasympathetic nervous system becomes dominant during the night, the IOP-lowering effect of $\beta$ blocker may be reduced during the nighttime, resulting in a tendency of the IOP increase at night $[16,23]$. However, Gulati et al. examined the effects of a PG, $\beta$-blocker, and CAI on the aqueous humor dynamics in patients with ocular hypertension and found that all agents had a smaller effect during the night than during daytime [24]. It is possible that individual IOP-lowering effects of PG, $\beta$ blocker, and CAI are attenuated during nighttime, and concomitant use of these three agents may have further reduced the effect at night. Larsson et al. also reported that the effect of PG peaks 10-12 hours after administration [25]. Thus, the IOPlowering effect of PG could be suboptimal during nighttime in patients who were administered PG eye drop at night.

In this study, subjects with high myopia (HM) and those with low or no myopia (LNM) were compared in a subanalysis. There were no significant differences in the IOP between the two groups at all time points, but the daytime IOP tended 
to be lower in the LNM group than in the HM group. In addition, a significant rise in the IOP was observed during the night in the LNM group. Previous literatures have suggested that IOP tends to be higher in myopic patients who have a long eye axis, than in emmetropic or hyperopic patients who have a short eye axis $[26,27]$. We found similar results during daytime in patients on triple eye drop treatment, but the IOP at 1:00 and 3:00 was higher in the LNM group.

Loewen et al. studied three groups of healthy individuals with spherical equivalent $\geq+1 \mathrm{D}$ (hyperopia), $-2 \mathrm{D}$ to 0 (emmetropia), and $\leq-3 \mathrm{D}$ (myopia), comparing visual field during daytime in sitting position and during nighttime in supine position, as well as the 24-hour IOP in supine position [11]. They found more prominent variation in the hyperopia group than in the other groups, and nighttime increases in IOP in the former group. Similarly, we found a tendency toward nighttime IOP increase in patients with hyperopia, even though all subjects were on medications and IOP was measured in the sitting position.

The mechanisms underlying nighttime IOP increase in hyperopia individuals remain unclear, regardless of nontreatment and treatment. Read et al. reported that the eye axis length reaches a minimum during the night and that the eye axis length correlates with daily IOP variation [28]. Such circadian changes in the eye axis length may have induced nighttime IOP increases in hyperopia individuals in whom the eye axis length is already short. Although all patients were examined by gonioscopy and those with synechial angle closure were excluded from this study, it is possible that the nonmyopic subjects with a shallow anterior chamber were prone to have functional angle closure causing increases in outflow resistance and nighttime IOP.

There are some limitations to this study. This study examined 24-hour IOP variation in patients treated with triple eye drops, but subjects with progressive visual field loss despite therapy may have been included. Other limitations include variations in eye drop type and number of eye drop instillations among subjects. In this study, we measured IOP in the sitting position at all time points. Significant elevation of IOP in the supine position during sleep at night has been reported [29-31]. There is no doubt that measuring IOP in different measurement positions in daily life is important in studying 24-hour IOP variation. However, a Goldmann applanation tonometer is still considered to give a greater precision and has remained the clinical standard for the care of glaucoma patients, and Liu et al. reported IOP variation of the sitting position to predict the IOP variation in the supine position [32]. We think that it is meaningful to know the tendency of nighttime IOP by sitting position measurement with triple eye drop treatment. Further studies are needed to answer the following intriguing questions: how IOP changes depending on the measurement position in daily living and how nighttime IOP elevation impacts the progression of visual field loss.

\section{Conclusions}

We measured 24-hour IOP variation in POAG patients treated with triple eye drops (PG, $\beta$-blocker, and CAI). The peak IOP was observed outside clinic hours in many eyes. Furthermore, our study showed that nighttime IOP increases even during triple eye drop treatment, especially in patients with spherical equivalent of $-2 \mathrm{D}$ or less. Because changes in IOP could be a potential risk factor for progression of visual field loss $[33,34]$, careful observation is required especially for low- or nonmyopic patients who are at risk of nighttime IOP elevation even during triple eye drop treatment.

\section{Conflicts of Interest}

The authors declare that there is no conflict of interest regarding the publication of this paper.

\section{Acknowledgments}

The authors thank Takumi Fukuda for clinical evaluation of the patients. This work was supported by JSPS Grant-in-Aid for Young Scientists (B) (26870605 (Hiroshi Horiguchi) and 17K18131 (Shumpei Ogawa)).

\section{References}

[1] Collaborative Normal-Tension Glaucoma Study Group, "The effectiveness of intraocular pressure reduction in the treatment of normal-tension glaucoma. Collaborative normal-tension glaucoma study group," American Journal of Ophthalmology, vol. 126, no. 4, pp. 498-505, 1998.

[2] M. A. Kass, D. K. Heuer, E. J. Higginbotham et al., "The ocular hypertension treatment study: a randomized trial determines that topical ocular hypotensive medication delays or prevents the onset of primary open-angle glaucoma," Archives of Ophthalmology, vol. 120, no. 6, pp. 701-713, 2002, discussion 829-730.

[3] M. C. Leske, A. Heijl, M. Hussein et al., "Factors for glaucoma progression and the effect of treatment: the early manifest glaucoma trial," Archives of Ophthalmology, vol. 121, no. 1, pp. 48-56, 2003.

[4] A. Heijl, "Glaucoma treatment: by the highest level of evidence," Lancet, vol. 385, no. 9975, pp. 1264-1266, 2015.

[5] A. Maslenikow, "Ueber Tagesschwankungen des Intraokularen Druckes bei Glaukom," Z Augenheilkd, vol. 11, p. 564, 1904.

[6] G. R. Reiss, D. A. Lee, J. E. Topper, and R. F. Brubaker, "Aqueous humor flow during sleep," Investigative Ophthalmology \& Visual Science, vol. 25, no. 6, pp. 776-778, 1984.

[7] D. S. Gregory, D. G. Aviado, and M. L. Sears, "Cervical ganglionectomy alters the circadian rhythm of intraocular pressure in New Zealand white rabbits," Current eye Research, vol. 4, no. 12, pp. 1273-1279, 1985.

[8] T. Yoshitomi and D. S. Gregory, "Ocular adrenergic nerves contribute to control of the circadian rhythm of aqueous flow in rabbits," Investigative Ophthalmology \& Visual Science, vol. 32, no. 3, pp. 523-528, 1991.

[9] T. Yoshitomi, B. Horio, and D. S. Gregory, "Changes in aqueous norepinephrine and cyclic adenosine monophosphate during the circadian cycle in rabbits," Investigative Ophthalmology \& Visual Science, vol. 32, no. 5, pp. 1609-1613, 1991.

[10] J. H. Liu, "Circadian rhythm of intraocular pressure," Journal of Glaucoma, vol. 7, no. 2, pp. 141-147, 1998. 
[11] N. A. Loewen, J. H. Liu, and R. N. Weinreb, "Increased 24-hour variation of human intraocular pressure with short axial length," Investigative Ophthalmology \& Visual Science, vol. 51, no. 2, pp. 933-937, 2010.

[12] A. G. Konstas, L. Quaranta, D. G. Mikropoulos et al., "Peak intraocular pressure and glaucomatous progression in primary open-angle glaucoma," Journal of Ocular Pharmacology and Therapeutics, vol. 28, no. 1, pp. 26-32, 2012.

[13] E. Hughes, P. Spry, and J. Diamond, "24-hour monitoring of intraocular pressure in glaucoma management: a retrospective review," Journal of Glaucoma, vol. 12, no. 3, pp. 232-236, 2003.

[14] Y. Barkana, S. Anis, J. Liebmann, C. Tello, and R. Ritch, "Clinical utility of intraocular pressure monitoring outside of normal office hours in patients with glaucoma," Archives of Ophthalmology, vol. 124, no. 6, pp. 793-797, 2006.

[15] S. Krag, H. B. Andersen, and T. Sorensen, "Circadian intraocular pressure variation with beta-blockers," Acta Ophthalmologica Scandinavica, vol. 77, no. 5, pp. 500-503, 1999.

[16] N. Orzalesi, L. Rossetti, T. Invernizzi, A. Bottoli, and A. Autelitano, "Effect of timolol, latanoprost, and dorzolamide on circadian IOP in glaucoma or ocular hypertension," Investigative Ophthalmology \& Visual Science, vol. 41, no. 9, pp. 25662573, 2000.

[17] K. Nakamoto and N. Yasuda, "Effect of carteolol hydrochloride on 24-hour variation of intraocular pressure in normal-tension glaucoma," Japanese Journal of Ophthalmology, vol. 54, no. 2, pp. 140-143, 2010.

[18] C. Tamer and H. Oksuz, "Circadian intraocular pressure control with dorzolamide versus timolol maleate add-on treatments in primary open-angle glaucoma patients using latanoprost," Ophthalmic Research, vol. 39, no. 1, pp. 24-31, 2007.

[19] K. Nakamoto and N. Yasuda, "Effect of concomitant use of latanoprost and brinzolamide on 24-hour variation of IOP in normal-tension glaucoma," Journal of Glaucoma, vol. 16, no. 4, pp. 352-357, 2007.

[20] S. Nakakura, Y. Nomura, S. Ataka, and K. Shiraki, "Relation between office intraocular pressure and 24-hour intraocular pressure in patients with primary open-angle glaucoma treated with a combination of topical antiglaucoma eye drops," Journal of Glaucoma, vol. 16, no. 2, pp. 201-204, 2007.

[21] D. Anderson and V. Patella, Automated Static Perimetry, pp. 152-153, Mosby, St. Louis, 1999.

[22] A. G. Konstas, F. Topouzis, O. Leliopoulou et al., "24-hour intraocular pressure control with maximum medical therapy compared with surgery in patients with advanced open-angle glaucoma," Ophthalmology, vol. 113, no. 5, pp. 761-765, 2006.

[23] W. C. Stewart, A. G. Konstas, L. A. Nelson, and B. Kruft, "Meta-analysis of 24-hour intraocular pressure studies evaluating the efficacy of glaucoma medicines," Ophthalmology, vol. 115, no. 7, pp. 1117-1122. e1111, 2008.

[24] V. Gulati, S. Fan, M. Zhao, M. A. Maslonka, C. Gangahar, and C. B. Toris, "Diurnal and nocturnal variations in aqueous humor dynamics of patients with ocular hypertension undergoing medical therapy," Archives of Ophthalmology, vol. 130, no. 6, pp. 677-684, 2012.

[25] L. I. Larsson, H. K. Mishima, M. Takamatsu, N. Orzalesi, and L. Rossetti, "The effect of latanoprost on circadian intraocular pressure," Survey of Ophthalmology, vol. 47, Supplement 1, pp. S90-S96, 2002.
[26] A. Tomlinson and C. I. Phillips, "Applanation tension and axial length of the eyeball," The British Journal of Ophthalmology, vol. 54, no. 8, pp. 548-553, 1970.

[27] H. Nomura, F. Ando, N. Niino, H. Shimokata, and Y. Miyake, "The relationship between intraocular pressure and refractive error adjusting for age and central corneal thickness," Ophthalmic \& Physiological Optics, vol. 24, no. 1, pp. 41-45, 2004.

[28] S. A. Read, M. J. Collins, and D. R. Iskander, "Diurnal variation of axial length, intraocular pressure, and anterior eye biometrics," Investigative Ophthalmology \& Visual Science, vol. 49, no. 7, pp. 2911-2918, 2008.

[29] T. Hara, T. Hara, and T. Tsuru, "Increase of peak intraocular pressure during sleep in reproduced diurnal changes by posture," Archives of Ophthalmology, vol. 124, no. 2, pp. 165$168,2006$.

[30] T. Kiuchi, Y. Motoyama, and T. Oshika, "Relationship of progression of visual field damage to postural changes in intraocular pressure in patients with normal-tension glaucoma," Ophthalmology, vol. 113, no. 12, pp. 2150-2155, 2006.

[31] Y. R. Lee, M. S. Kook, S. G. Joe et al., "Circadian (24-hour) pattern of intraocular pressure and visual field damage in eyes with normal-tension glaucoma," Investigative Ophthalmology \& Visual Science, vol. 53, no. 2, pp. 881-887, 2012.

[32] J. H. Liu, R. P. Bouligny, D. F. Kripke, and R. N. Weinreb, "Nocturnal elevation of intraocular pressure is detectable in the sitting position," Investigative Ophthalmology \& Visual Science, vol. 44, no. 10, pp. 4439-4442, 2003.

[33] S. Asrani, R. Zeimer, J. Wilensky, D. Gieser, S. Vitale, and K. Lindenmuth, "Large diurnal fluctuations in intraocular pressure are an independent risk factor in patients with glaucoma," Journal of Glaucoma, vol. 9, no. 2, pp. 134-142, 2000.

[34] K. Nouri-Mahdavi, D. Hoffman, A. L. Coleman et al., "Predictive factors for glaucomatous visual field progression in the advanced glaucoma intervention study," Ophthalmology, vol. 111, no. 9, pp. 1627-1635, 2004. 


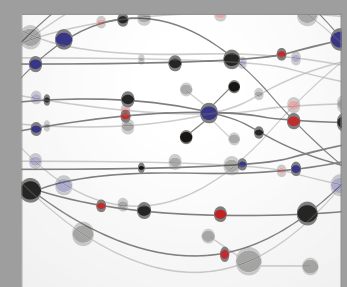

The Scientific World Journal
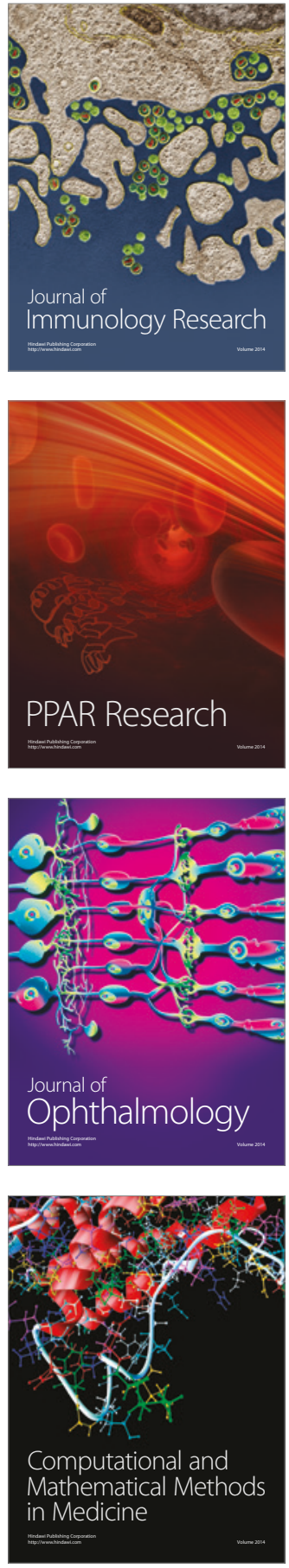

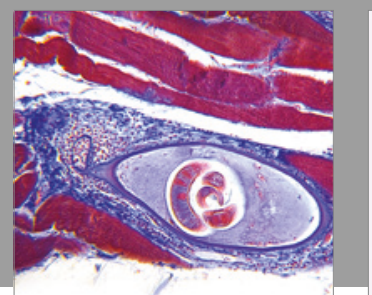

Gastroenterology Research and Practice
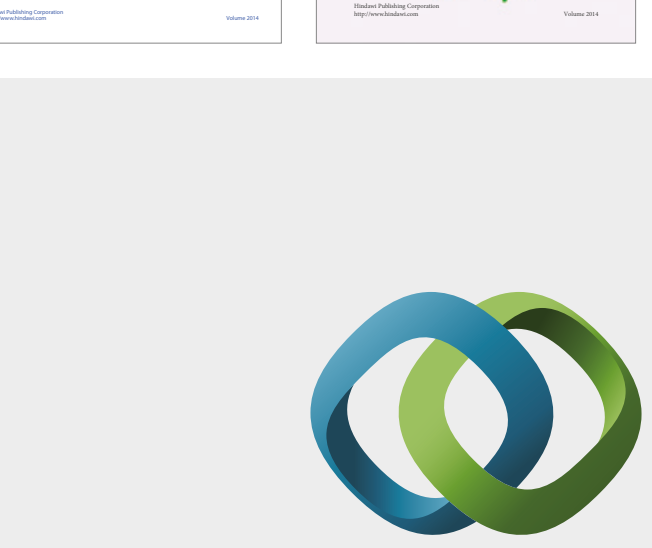

\section{Hindawi}

Submit your manuscripts at

https://www.hindawi.com
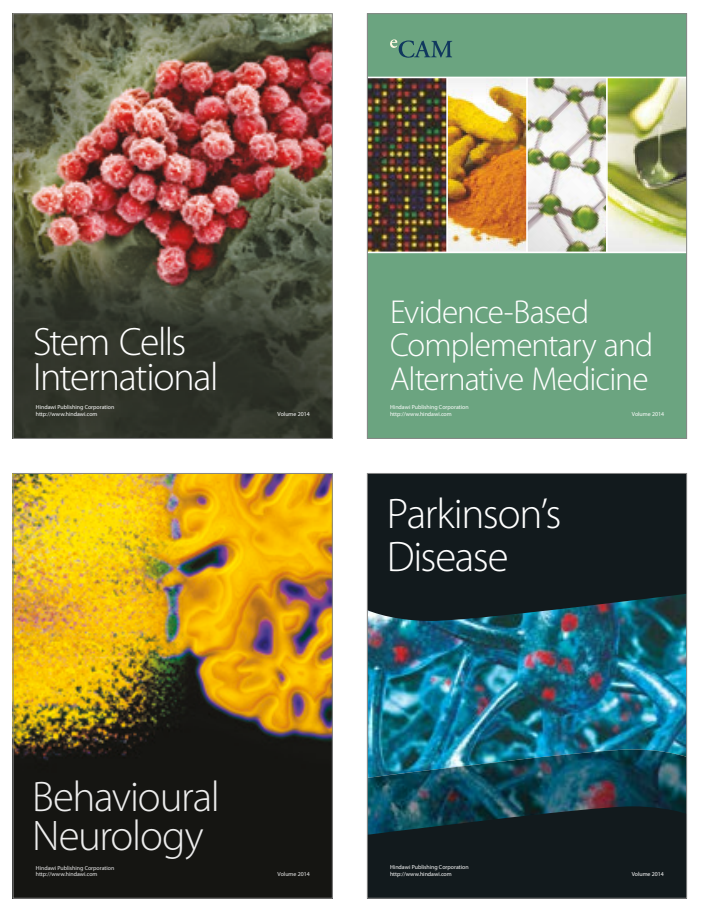
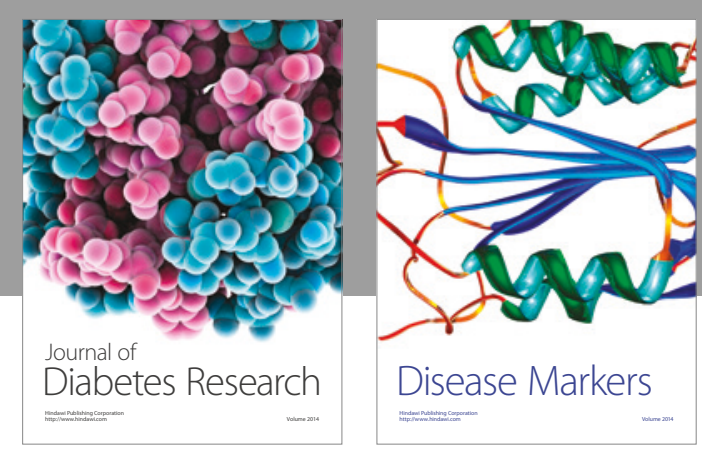

Disease Markers
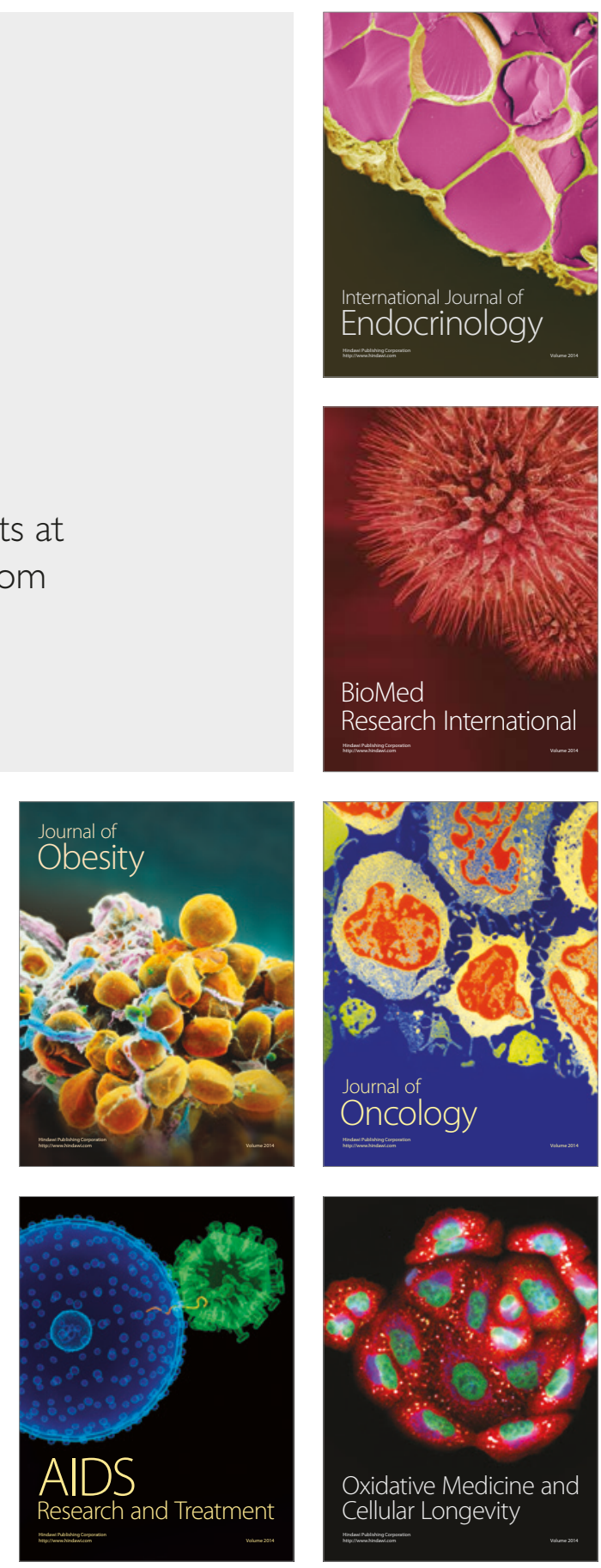